\title{
QUALITY OF LIFE OF KEY CAREGIVERS OF SCHIZOPHRENIA PATIENTS AND ASSOCIATION WITH KINSHIP
}

\author{
Branka Aukst Margetić1, Miro Jakovljević1, Zvjezdana Furjan², Branimir Margetićc ${ }^{2}$, Vlatka Boričević Maršanić ${ }^{3}$ \\ 'Department of Psychiatry, University Hospital Center, Zagreb, Croatia \\ ${ }^{2}$ Neuropsychiatric Hospital "Dr. Ivan Barbot", Popovača, Croatia \\ ${ }^{3}$ Psychiatric Hospital for Children and Youth, Zagreb, Croatia
}

\section{SUMMARY}

Introduction: Reports on the quality of life (QOL) of family caregivers of schizophrenia patients are uncommon. Relations of different degree of kinship to caregivers' QOL are unexplored, but may be relevant. The purpose of this study was to assess the subjective QOL of caregivers of stable outpatients with diagnosis of schizophrenia compared with controls, and to assess factors associated with QOL in this population.

Methods: Responses of 138 schizophrenia outpatient' family caregivers to the Quality of Life, Enjoyment and Satisfaction Questionnaire (QLESQSF) were compared with those of a sex- and age-matched control group. Patients were assessed with the Positive and Negative Symptom Scale (PANSS) and the Global Assessment of Functioning (GAF) and data were collected for kinship relationship and hospitalization.

Results: Group of caregivers had significantly lower QOL compared with controls ( $t=11.347 ; \mathrm{df}=271 ; \mathrm{p}=0.0001$ ). Caregivers' $\mathrm{QOL}$ correlated significantly with their age and differed according to the degree of kinship and marriage status. ANCOVA, with age as covariate, performed to asses the differences in QOL according to kinship, showed that parents and own children had significantly lower QOL than patients' siblings who were also caregivers.

Conclusion: QOL of the schizophrenia patients' caregivers is lower in comparisons to controls. It depends on the degree of kinship and caregivers' age. Parents and own children have lower QOL than siblings. Psycho-educational intervention programmes should target specific needs of the family as a whole, depending also on their age and kinship relationship.

Key words: QOL, schizophrenia, key caregivers, family, kinship

Address for correspondence: B. Aukst Margetić, Department of Psychiatry, University Hospital Center, 10000 Zagreb, Croatia. E-mail: branka. aukst-margetic@zg.t-com.hr

\section{INTRODUCTION}

Owing to inadequacy of community-based services, family of origin remains the most important social contact and source of support for the majority of schizophrenia patients. The impact of caring for a relative with a mental disorder on the quality of life (QOL) of family caregivers has been acknowledged in previous reports (1-3). It has been shown that schizophrenia patients' family caregivers have lower scores on measures of quality of life comparing to caregivers of the patients with other psychiatric diagnoses $(4,5)$. Their low QOL derives from emotional reactions to the illness, the stress of coping with relatives' disturbed behaviour, the disruption of household routine, stigma they are also confronted with, restriction in social and leisure activities, and economic difficulties (6).

QOL of caregivers of patients with schizophrenia has been associated with gender (women have lower scores), caregiver state of health, positive appraisal of their role, subjective burden, and social support $(1,4)$. It is shown that relatives' and patients' QOL are lower than QOL of the general population (7), but it is unclear whether and how characteristics of the patient relate to caregivers' QOL.

There is a difference in involvement in caring process between family members of patients with schizophrenia. In most cases it is the mother who takes the most of responsibilities in caring for the patient (8). In the study of Kurs et al. (9) there was no difference in domains of QOL between siblings of patients with schizophrenia and control subjects, but it was not clear from the study if the siblings were also the caregivers. Parents showed lower QOL comparing to other family members in the study of Awadala et al. (4), but other family members were not differentiated according to kinship status.

Gutiérrez-Maldonado et al. (10) identified kinship status as a significant predictor of relatives' subjective burden, a concept related with QOL. Nevertheless, it is not clear if and how the differences in kinship may be related to differences in their QOL.

Our aim was to assess differences in QOL between the group of patient's caregivers and control subjects and to assess if certain characteristics of the caregivers and the patients could be associated with caregivers' QOL.

\section{MATERIALS AND METHODS}

A hundred and thirty eight schizophrenia patients' firstdegree relatives ( $36.2 \%$ male), the same number of patients with diagnosis of schizophrenia ( $58.0 \%$ male), and healthy controls (37.2\% male), all Caucasians, were recruited consecutively over the course of fifteen months from two psychiatric institutions: 
University Hospital Center Zagreb and Neuropsychiatric hospital "Dr. Ivan Barbot". The diagnosis of schizophrenia was established according to DSM-IV criteria.

We assessed one relative per patient who was psychiatrically treated. Relatives were the key caregivers. The key caregiver is defined as the person who fulfils the following modified criteria of Magliano and coworkers: being older than 18 years and staying with the patient at least 5 hours a day, for a minimum of 5 days a week, at least one year (11). This group consisted of 64 mothers (46.4\%), 42 fathers (30.4\%), 12 sisters $(8.7 \%), 9$ brothers $(6.5 \%)$, 9 daughters $(6.5 \%)$, and two sons (1.4\%), and according to degree of kinship were categorised as parents, siblings and children. The control group consisted of healthy volunteers matched for gender and age with the relatives' group recruited from hospital medical and non-medical staff, students and visitors by word of mouth recruitment method. Only those who demonstrated no history of psychiatric illness and were not current caregivers were enrolled as healthy controls.

The relatives selected were those in company of the outpatients, who were in stable clinical condition, had been ill for at least one year, and could independently provide informed consent to participate. All participants gave written informed consent after receiving a comprehensive explanation on the nature of the study. The study was approved by ethics committees of the institutions and the ethical standards in accordance with Helsinki Declaration of 1975 (revised in 1983) were followed.

Eighteen relatives, who were approached, refused to participate and additional eleven were not able to complete the questionnaires. The reasons for non-participation were a lack of time or being uncomfortable with the length of assessment associated with the other parts of the study. There were no differences in age and gender between relatives included and those who refused to participate in this study.

The Quality of Life Enjoyment and Satisfaction QuestionnaireShort Form is a self-report instrument composed of 14 items each rated on a 5-point scale that indicates the degree of enjoyment or satisfaction experienced during the past week (row score range 14-70) (12). The translation of the original version into Croatian was carried out following the guidelines developed by WHO (World Health Organization) (13). The items evaluated subjects' satisfaction with his or her physical health, social relations, ability to function in daily life, ability to get around physically, mood, family relations, sexual drive and interest, ability to work on hobbies, leisure time activities, work, economic status, household activities, living/housing situation, and overall sense of well-being. The item of medication satisfaction was not included, as it is not applicable to both groups. Cronbach alpha in this sample was 0.9.

The patients were assessed with the Positive and Negative Syndrome Scale (PANSS) (14) for the purposes of evaluating the severity of general psychopathology and positive and negative syndromes. The instrument consists of 30 items, with each item rated on a seven-point severity scale. This is an intervieweradministered scale scored on the basis of a clinical interview lasting 30-45 minutes and performed by an experienced research psychiatrist. The instrument's reliability and validity is well established (14). It has a high level of internal reliability in this sample with Cronbach alpha being 0.89 . We also collected data about length of illness and number of hospitalizations of the patients from the medical records.
The Global Assessment of Functioning (GAF) is a part of DSM-IV. Level of functioning is assessed on a 0-100 scale where 100 marks the highest level of functioning (15). This scale evaluates psychological, social and occupational functioning on hypothetical continuum of mental health. The worst state on any of three dimensions implies final general score.

\section{Statistics}

All analyses were performed using SPSS 16.0. The differences between groups of relatives and controls were evaluated using t-test, as the distribution of QOL in the groups was normal. Caregivers' QOL was correlated with relatives' age and patient related variables: age, psychopathology, length of illness and number of hospitalizations, and global assessment of functioning. Differences in QOL according to categorical socio-demographic variables were assessed with ANOVA.

ANCOVA was used to assess the differences between the kinship categories in QOL controlled for previously significant correlation of QOL with relatives' age.

For all analyses, the level of statistical significance was defined as an alpha less than 0.05 .

\section{RESULTS}

The mean age or the relatives group was 52.6 years $(\mathrm{SD}=14.4)$; the controls $51.2(\mathrm{SD}=15.25)$; and the mean QOL of the caregivers $50.5(\mathrm{SD}=5.45)$ and controls mean $57.5(\mathrm{SD}=4.78)$. Patients characteristic: age, PANSS and its subscales, GAF, length of illness and a number of hospitalizations are presented in Table 1.

Caregivers and controls differed significantly in QOL $(\mathrm{t}=11.347$; $\mathrm{df}=271 ; \mathrm{p}=0.0001)$ and the group of patients' relatives had significantly lower QOL. They also differed in all items of QOL.

Caregivers' QOL correlated (negatively) significantly only with their age $(r=-0.464 ; \mathrm{p}=0.0001)$, but not with patients' characteristics: PANSS global and its subscales: positive, negative and general, GAF, length of illness and a number of hospitalizations. QOL differed according to degree of kinship $(\mathrm{F}=20.320$; $\mathrm{df}=2,138$; $\mathrm{p}=0.0001)$, marriage status $(\mathrm{F}=4.999 ; \mathrm{df}=3,138 ; \mathrm{p}=0.003)$ and education $(\mathrm{F}=3.852 ; \mathrm{df}=3,138 ; \mathrm{p}=0.011)$.

ANCOVA using age as covariate was performed to distinguish differences in QOL of the relatives based on kinship (parents, siblings, children), education and marriage status, showing parents and children to have significantly lower QOL than siblings $(\mathrm{F}=3.567 ; \mathrm{df}=2 ; 138 ; \mathrm{p}=0.031)$. Differences in QOL based on education and marriage status were dependent on relatives' age. Results are shown in Table 2.

\section{DISCUSSION}

To our knowledge, this is the first study that assessed relationship of kinship with QOL in the group of schizophrenia patients' relatives. QOL of the patients' caregivers is lower than in the control group as shown in several studies before $(4,16)$ and our results corroborate the findings. However, the results of our study show that group of caregivers is not homogeneous and that parents and children have lower QOL than siblings. 
Table 1. Sociodemographic characteristics of the caregivers' sample

\begin{tabular}{|c|c|c|c|}
\hline Variable & $\mathbf{N}$ & $\%$ & Mean (SD) \\
\hline \multicolumn{4}{|l|}{ Gender } \\
\hline Male & 50 & 36.2 & \\
\hline Education & 31 & 22.5 & \\
\hline Primary & 69 & 50.0 & \\
\hline Secondary & 19 & 13.8 & \\
\hline Higher & 19 & 13.8 & \\
\hline \multicolumn{4}{|l|}{ High } \\
\hline \multicolumn{4}{|l|}{ Marriage } \\
\hline Married & 90 & 65.2 & \\
\hline Single & 19 & 13.8 & \\
\hline Divorced & 10 & 7.2 & \\
\hline Widowed & 19 & 13.8 & \\
\hline \multicolumn{4}{|l|}{ Kinship status } \\
\hline Parents & 106 & 76.8 & \\
\hline Siblings & 21 & 15.2 & \\
\hline Children & 11 & 7.9 & \\
\hline \multicolumn{4}{|l|}{ Patients characteristics } \\
\hline Age & & & $34.1(10.61)$ \\
\hline PANSS & & & $67.4(13.70)$ \\
\hline Positive & & & $13.2(4.38)$ \\
\hline Negative & & & $18.1(5.29)$ \\
\hline General & & & $35.8(7.39)$ \\
\hline GAF & & & $65.4(9.87)$ \\
\hline Length of illness & & & $7.8(7.15)$ \\
\hline Number of hospitalizations & & & $3.9(4.20)$ \\
\hline
\end{tabular}

Table 2. Results of ANCOVA with age as covariate $d f(2,138)$

\begin{tabular}{|l|c|c|}
\hline & Test (F) & $\mathbf{p}$ \\
\hline Kinship & 3.567 & 0.031 \\
\hline Education & 1.935 & 0.127 \\
\hline Marriage & 0.606 & 0.612 \\
\hline
\end{tabular}

The results are in agreement with results of Awadala et al., (4) who showed that parents of the patients with mental illness had lower QOL compared with other categories and with GutiérrezMaldonado et al. (10) who assessed the relationship of kinship with similar concept of burden of care. The study shows that the age of relatives negatively correlates with QOL, which is in accordance with previous knowledge (4). Accordingly, the differences in age between the groups could have biased the results. The differences in QOL between caregivers according to kinship persisted after being adjusted for age, although some bias could still exist.

As a result of deinstitutionalization, and the increasing shift of psychiatric care to community, many individuals with mental illness rely on their families for support because of the absence of adequate community-based services. Even today, despite the presence of a greater array of community-based services, family members, in particular parents, often step in to fill the gaps in the service system (17). Patients with schizophrenia due to illness burden seldom have children to take care for them. The studies that included children as caregivers are rare. This category is underrepresented in all so far published studies $(4,10,17)$ as well as in our study. Our results show that parents and children have similarly low level of QOL. The difference between parents and children category and category of siblings may arise due to higher emotional engagement and attachment between parents and children comparing to siblings. The parents' low QOL may reflect, among other, their worry about possible relapse, feeling of personal responsibility for the illness because of poor parenting, worries regarding the future related to their permanent responsibility for the patient and the question of who will take care of the patient if they no longer can (18). Children of the patients may worry about possibility to inherit the illness. Whether such worries in the siblings group are less pronounced is unclear, but the finding about siblings having similar QOL as controls was published in the study of Kurs et al. (9). The interaction of different genetic loading and environmental influences leads to differences in susceptibility to stress in parents, children and siblings and may also reflect QOL differences (19). The differences and specificities in their needs, burden and QOL should be recognized and met in psycho-educational intervention programmes (17).

We found that patients' clinical characteristics were not significantly associated with caregivers' QOL scores. This may be partly due to the fact that the schizophrenia patients group included clinically stable patients, so the burden of dealing with an acute schizophrenic relative on a daily basis was minimized. Namely, studies show that the most important predictor of the burden on relatives was the distress and changes in the relationship between caregiver and the affected individual that occur during acute phase of the illness $(6,20)$. Further, cross-sectional clinical ratings of psychopathology may not give sufficient insight into the extent of patients' symptoms and behaviours experienced by the relatives which may fluctuate on a daily basis.

The data about relationship between relatives QOL and patients' clinical characteristics are sparse (21). The literature on similar constructs as relatives' subjective burden shows conflicting results (22-24). This implies that longitudinal studies should be carried out to assess the impact of psychopathology on QOL according to stage of illness. Moreover, the sample of patients is considerably heterogeneous in terms of age and the length of disease. Therefore, the kinship relationships in general and the quality of relationship between the identified patient and the key caregiver might differ. Studies have shown that the level of burden can change over time and so can the coping strategies that key caregivers use (25).Younger relatives and relatives of younger patients used more problem-focused strategies while relatives who had been living with a patient for a long time or had lower social support and less professional help used more emotion-focused strategies (26) associated with lower QOL (27).

Although the schizophrenic patients' caregivers have lower QOL than other caregivers $(4,5)$, the study showed that characteristics of the patient related to illness are less important than the caregivers' age or kinship. Focus on kinship relationship is important, but somewhat neglected in the research on caregiving for patients with schizophrenia. Parents and own children may be more vulnerable to depression and anxiety, while siblings need more motivational approach in psycho-educational programmes. Our results implicate that all family members need to be properly 
informed about the patient's illness and share their concerns with professionals and that the psycho-educational programmes should be offered to the whole family.

\section{Limitations}

The study has several limitations. Its design is cross-sectional and only one relative per patient was assessed. Also, our study did not include measure of burden, and assessed the differences if the patient and relative lived together or the caregiver visited the patient regularly for his caregiving duties. Another potentially important issue that was not taken into account is the number of family members, besides key caregiver, that can share the burden of care for the ill member. The characteristics of caregivers which may have impact on their QOL were not assessed (as physical and mental health status). The group of children caregivers is underrepresented as patients with schizophrenia tend not to marry and in families with children the patients' spouses are serving as caregivers (28).

The future studies should focus on a control group. Our control group matched key relatives according to age and gender, but to asses QOL of the caregivers of patient with schizophrenia more specifically, control group should include persons that also have caregiving responsibilities.

Finally, measuring of QOL in this population should include instruments that would measure various aspects of QOL (not only subjective) as well as measures of functional impairment.

\section{CONCLUSION}

Parents, children and siblings relate differently to patients and may be differently affected by the burden of care. Adults with schizophrenia will likely look to their siblings or children for support, as their aging parents' capacity to provide care diminishes and ultimately ends (29). An implication of our findings may be that psycho-educational intervention programmes should target specific needs of family caregivers, depending on their age and kinship relationship. Accordingly, it is necessary to extend the study and perform intensive research (including qualitative data based on focus groups and/or individual interviews) and then modify psycho-educational programmes in order to fit all relatives' needs.

\section{Conflict of Interests}

None declared

\section{REFERENCES}

1. Guethmundsson OO, Tómasson K. Quality of life and mental health of parents of children with mental health problems. Nord J Psychiatry. 2002;56(6):413-7.

2. Heru AM, Ryan CE, Vlastos K. Quality of life and family functioning in caregivers of relatives with mood disorders. Psychiatr Rehabil J. 2004 Summer;28(1):67-71

3. Ohaeri JU. The burden of caregiving in families with a mental illness: a review of 2002. Curr Opin Psychiatry. 2003;16(4):457-65.

4. Awadalla AW, Ohaeri JU, Salih AA, Tawfiq AM. Subjective quality of life of family caregivers of community living Sudanese psychiatric patients. Soc Psychiatry Psychiatr Epidemiol. 2005 Sep;40(9):755-63.

5. Li L, Young D, Xiao S, Zhou X, Zhou L. Psychometric properties of the WHO Quality of Life questionnaire (WHOQOL-100) in patients with chronic diseases and their caregivers in China. Bull World Health Organ. $2004 \mathrm{Jul} ; 82(7): 493-502$.
6. Rössler W, Salize HJ, van Os J, Riecher-Rössler A. Size of burden of schizophrenia and psychotic disorders. Eur Neuropsychopharmacol. 2005 Aug;15(4):399-409.

7. Margetić BA, Jakovljević M, Ivanec D, Margetić B. Temperament, character, and quality of life in patients with schizophrenia and their first-degree relatives. Compr Psychiatry. 2011;52(4):425-30.

8. Bloch S, Szmukler GI, Herrman H, Benson A, Colussa S. Counseling caregivers of relatives with schizophrenia: themes, interventions, and caveats. Fam Process. 1995 Dec;34(4):413-25.

9. Kurs R, Farkas H, Ritsner M. Quality of life and temperament factors in schizophrenia: comparative study of patients, their siblings and controls. Qual Life Res. 2005 Mar;14(2):433-40.

10. Gutiérrez-Maldonado J, Caqueo-Urízar A, Kavanagh DJ. Burden of care and general health in families of patients with schizophrenia. Soc Psychiatry Psychiatr Epidemiol. 2005 Nov;40(11):899-904.

11. Magliano L, Veltro F, Guarneri M, Marasco C. Clinical and sociodemographic correlates of coping strategies in relatives of schizophrenic patients. Eur Psychiatry. 1995;10(3):155-8.

12. Endicott J, Nee J, Harrison W, Blumenthal R. Quality of Life Enjoyment and Satisfaction Questionnaire: a new measure. Psychopharmacol Bull. 1993;29(2):321-6.

13. Sartorius N, Kuyken W, Orley J. Translation of health status instruments. In: Orley J, Kuyken W, editors. Quality of life assessment: international perspectives: joint meeting: papers; 1993 Jul; Paris. Berlin: Springer; 1994. p. 3-18.

14. Kay SR, Fiszbein A, Opler LA. The positive and negative syndrome scale (PANSS) for schizophrenia. Schizophr Bull. 1987;13(2):261-76.

15. American Psychiatric Association. Diagnostic and statistical manual of mental disorders, DSM-IV-TR. 4th ed. Washington: American Psychiatric Association; 2000.

16. Foldemo A, Gullberg M, Ek AC, Bogren L. Quality of life and burden in parents of outpatients with schizophrenia. Soc Psychiatry Psychiatr Epidemiol. 2005 Feb;40(2):133-8.

17. Koukia E, Madianos MG. Is psychosocial rehabilitation of schizophrenic patients preventing family burden? A comparative study. J Psychiatr Ment Health Nurs. 2005 Aug;12(4):415-22.

18. Jungbauer J, Wittmund B, Dietrich S, Angermeyer MC. Subjective burden over 12 months in parents of patients with schizophrenia. Arch Psychiatr Nurs. 2003 Jun;17(3):126-34.

19. Tsuang MT, Stone WS, Gamma F, Faraone SV. Schizotaxia: current status and future directions. Curr Psychiatry Rep. 2003 Jun;5(2):128-34.

20. Lauber C, Eichenberger A, Luginbühl P, Keller C, Rössler W. Determinants of burden in caregivers of patients with exacerbating schizophrenia. Eur Psychiatry. 2003 Oct;18(6):285-9.

21. Caqueo-Urízar A, Gutiérrez-Maldonado J, Miranda-Castillo C. Quality of life in caregivers of patients with schizophrenia: a literature review. Health Qual Life Outcomes. 2009 Sep 11;7:84.

22. Tang VW, Leung SK, Lam LC. Clinical correlates of the caregiving experience for Chinese caregivers of patients with schizophrenia. Soc Psychiatry Psychiatr Epidemiol. 2008 Sep;43(9):720-6.

23. Grandón P, Jenaro C, Lemos S. Primary caregivers of schizophrenia outpatients: burden and predictor variables. Psychiatry Res. $2008 \mathrm{Apr}$ $15 ; 158(3): 335-43$.

24. Möller-Leimkühler AM, Wiesheu A. Caregiver burden in chronic mental illness: the role of patient and caregiver characteristics. Eur Arch Psychiatry Clin Neurosci. 2012 Mar;262(2):157-66.

25. Magliano L, Fadden G, Economou M, Held T, Xavier M, Guarneri M, et al. Family burden and coping strategies in schizophrenia: 1-year followup data from the BIOMED I study. Soc Psychiatry Psychiatr Epidemiol. 2000 Mar;35(3):109-15.

26. Magliano L, Fadden G, Economou M, Xavier M, Held T, Guarneri M, et al. Social and clinical factors influencing the choice of coping strategies in relatives of patients with schizophrenia: results of the BIOMED I study. Soc Psychiatry Psychiatr Epidemiol. 1998 Sep;33(9):413-9.

27. Kate N, Grover S, Kulhara P, Nehra R. Relationship of quality of life with coping and burden in primary caregivers of patients with schizophrenia. Int J Soc Psychiatry. In press.

28. Nanko S, Moridaira J. Reproductive rates in schizophrenic outpatients. Acta Psychiatr Scand. 1993 Jun;87(6):400-4.

29. Smith MJ, Greenberg JS. Factors contributing to the quality of sibling relationships for adults with schizophrenia. Psychiatr Serv. 2008 Jan;59(1):57-62. 